Original Research

\title{
Soil Organic Carbon, Aggregates, and Fractions under Different Land Uses in the Loess Plateau, China
}

\author{
Zhi Qu ${ }^{1,2}$, Rui Jiang1,2*, Kun Wang1, Ming Li ${ }^{1,2}$ \\ ${ }^{1}$ College of Natural Resources and Environment, Northwest A\&F University, Yangling, P.R. China \\ ${ }^{2}$ Key Laboratory of Plant Nutrition and the Agri-environment in Northwest China, Ministry of Agriculture, China
}

Received: 15 January 2018

Accepted: 18 April 2018

\begin{abstract}
The dynamics of soil organic carbon (SOC) under different land uses can be beneficial for accurately assessing carbon sequestration to deal with global climate change. The aim of this study was to quantify the SOC content in various fractions under different land uses. Soil samples were collected from the top $0.1 \mathrm{~m}$ and $0.1-0.3 \mathrm{~m}$ of cropland, grassland, and forest in Huachi County of Gansu Province, China. Significant differences in physical fractions were found in the top 0.1-m layer, with cropland having the highest proportion of micro-aggregates $(<250 \mu \mathrm{m})$, forest having the highest proportion of small macro-aggregates $(250-2000 \mu \mathrm{m})$, and grassland tending to form large macro-aggregates $(>2000 \mu \mathrm{m})$. SOC values were $6.9,11.3$, and $10.3 \mathrm{~g} \mathrm{~kg}^{-1}$ in the top $0.1-\mathrm{m}$ layer for cropland, grassland, and forest, respectively. The difference in $\delta^{13} \mathrm{C}$ between the light and heavy fraction in small macro-aggregates was smaller than that in both large macro-aggregates and micro-aggregates. These results indicated that small macro-aggregates conserved SOC relative to micro-aggregates and large macro-aggregates. The differences in $\delta^{13} \mathrm{C}$ between the light and heavy fraction in all aggregate size fractions of grassland were much larger than in forest, indicating that there was higher microbial decomposition in grasslands. Overall, our results suggested that the accumulation of SOC in grassland was derived from the abundant carbon input, but the protection of SOC from small macro-aggregates was important to forest soil.
\end{abstract}

Keywords: soil organic carbon, aggregate, density fraction, land use, Loess Plateau

\section{Introduction}

Land use change is an important factor affecting soil organic carbon (SOC). Intensive decomposition of the SOC occurs when natural grassland and woodland change to cropland. In contrast, conversion of cropland to grassland or woodland causes a gradual increase in the SOC pool $[1,2]$. In the context of global climate change, many researchers have begun to pay attention to controlling SOC storage by changing the land use types to mitigate carbon dioxide emissions [3-5]. Therefore, knowledge regarding the effects of land use changes on SOC is important for implementing these practical works.

*e-mail: jiangrui@nwsuaf.edu.cn 
It has generally been found that the SOC distribution was lower in cropland than forest, shrub land, and grassland [6-9] due to the low litter input in long-term cultivation of cropland [5]. Especially when young forest was included in the SOC sequence, this forest could record higher SOC levels than cropland [10]. However, some exceptions to these results have been reported that converting cropland to forest was associated with a loss of SOC [11-13]. In addition, no significant differences in the influence of different vegetation types on SOC were also reported sometimes [14].

All above findings showed that results in different regions can be contradictory, which likely occurs because of complex terrain, climate, and soil environment [15]. Therefore, revealing the reasons for the above variation and dynamics of SOC under different land uses in the same region can be beneficial for accurately assessing carbon sequestration, as well as developing soil management techniques to deal with global climate change.

The SOC content is dependent on the litter input and degradation rate of existing SOC. It is well known that the litter input in cropland was much lower than that in grassland and forest. Fan et al. [16] found that the SOC content remained stable during 26 years of cultivation when only mineral nitrogen fertilizer was applied. They suggested that the contribution of litter to SOC input was extremely limited in cropland because it was rapidly decomposed. Zhang et al. [17] compared the dynamics of SOC in grass, shrub, young forest, and mature secondary forest ecosystems in Qinling Mountains and found that the accumulation of organic matter in the litter layer was related to the decrease in decomposition of litter. Taken together, these findings indicate that the stabilization of SOC should be considered further.
Aggregates are important factors affecting the persistence of SOC. Six et al. [18] indicated that the SOC content in macroaggregate was 1.65 times greater compared to microaggregate in cropland. An et al. [19] also found that macroaggregates had a higher SOC content than microaggregates in both forest and abandoned grazing land on the Loess Plateau. Gunina and Kuzyakov [20] reported that the C flows in the small macro and microaggregate size was more intensive than large macroaggregate, indicating a faster microbial decomposition rate in macroaggregate compared to microaggregate. Thus, it is possible to distinguish between stable organic carbon and readily mineralized organic carbon based on the SOC particle size [21].

In addition, the density fraction and stable $\mathrm{C}$ isotope analysis $\left({ }^{13} \mathrm{C} /{ }^{12} \mathrm{C}\right)$ have been successfully used to elucidate SOC dynamics [22]. The heavy fractions were always considered as microbial transformation products of the lighter fractions [20]. The density fraction dynamics in aggreagete could also illustrate SOC variations in aggregates. Tan et al. [23] found that the mass of light fraction significantly increased along with the increased aggregate size. They also found that the percentage of heavy fraction $\mathrm{C}$ in forest was lower than that in conventional tillage cropland. Therefore, integrating size fraction and density fraction methods may be useful for understanding the SOC content and dynamics.

The aims of this study were to quantify the SOC content in various fractions under different land uses, and to evaluate the effects of carbon input and degradation on SOC distribution in various fractions in different land use. The SOC content and dynamics were analyzed in areas of different land uses based on: i) soil physical fractions under different land uses, ii) SOC content in bulk soil and different sizes of aggregates,

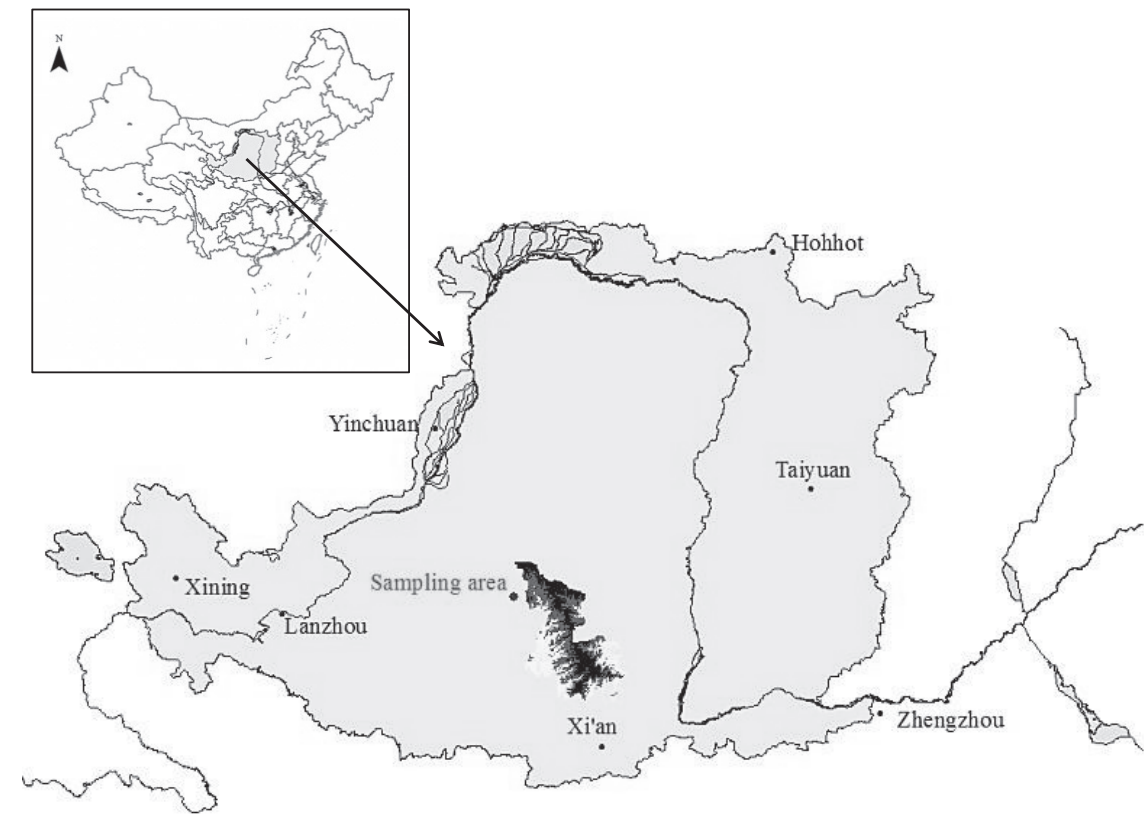

Fig. 1. Location of the study area in the Loess Plateau, China. 
and iii) stable carbon isotope composition and density fraction in different sizes of aggregates. The Loess Plateau $\left(6.2 \times 10^{5} \mathrm{~km}^{2}\right)$ was selected for study because it is known as the most severely eroded area in this region, and a large number of land use measurements are being carried out in this area.

\section{Materials and Methods}

\section{Study Area}

The investigation was carried out in Huachi County of Gansu Province, China (Fig. 1; E 107 $52^{\prime}-108^{\circ} 31^{\prime}$, $\left.\mathrm{N} 36^{\circ} 17^{\prime}-36^{\circ} 22^{\prime}\right)$. This county is located in western Ziwuling forest region situated in the middle part of the Loess Plateau, which is the largest natural forest region on the plateau. The area has a continental monsoon climate with an average annual temperature of $7.8^{\circ} \mathrm{C}$, annual precipitation of $445 \mathrm{~mm}$, and average frost-free period of 172 days from 2000 to 2012 (according to the Huachi County Meteorological Bureau).

\section{Land Uses}

Three types of land uses (cropland, grassland, and forest) were selected in the current study. All the selected sites were distributed in the small valley plain. The loess layer in this valley plain is more than $60 \mathrm{~m}$ thick, having uniform soil parent materials with little spatial variation in silty clay. The soil type is a calcareous loamy soil, classified as Calcic Cambisols according to the Food and Agriculture Organization soil classification system. The bulk density of this soil is $1.28-1.32 \mathrm{~g} \mathrm{~cm}^{-3}$ and the clay content is about $23.7 \%$. The cropland was intensively cultivated for more than 60 years and the staple crop was maize. The dominant species in grassland were Stipa bungeana and Artemisia scoparia, and the vegetation cover was more than $80 \%$. An artificial woodland was selected as forest, and white poplar (Populus alba) was planted 30 years ago.

\section{Sampling}

Soil samples were collected from depths of 0-0.1 and 0.1-0.3 m using a stainless-steel cutting ring (0.05 m diameter, $0.65 \mathrm{~m}$ length) in August 2014.
For each site, three independent replications were collected from more than $200 \mathrm{~m}$ apart from each other. To obtain a representative sample, each replication consisted of a mixture of subsamples from four individual samples. All soil samples were air-dried at room temperature. Soil properties of soil samples collected from cropland, grassland, and forest are shown in Table 1. Soil homogeneity was assumed in the current study because all sites had the same soil type and similar topography.

\section{Physical Fractionation}

Aliquots of soil samples were accurately weighed to $100 \mathrm{~g}$ and then dry sieved through 2000 and $250-\mu \mathrm{m}$ meshes. Dry sieving was used to minimize the disruption of aggregates and provide results more representative of the field situation. Aggregate size classes $>2000$, 250-2000, and $<250 \mu \mathrm{m}$ were obtained. These fractions were defined as large macro-aggregate, small macro-aggregate, and micro-aggregate, respectively, according to Cambardella and Elliott [24]. Five grams of aggregates were placed into a centrifugation tube with $15 \mathrm{~mL}$ of sodium polytungstate (SPT) solution (the density was $1.85 \mathrm{~g} \mathrm{~cm}^{-3}$ ). The tube was gently inverted several times, and then centrifuged at $4,000 \mathrm{rpm}$ for $1 \mathrm{~h}$. To obtain a light fraction of organic matter $(\mathrm{OM})$ with a density $\rho<1.85 \mathrm{~g} \mathrm{~cm}^{-3}$, the supernatant with floating particles was filtered through a fiberglass membrane (GF/C, Whatman, UK) and washed with distilled water. The remaining soil was then washed four times with distilled water (20 $\mathrm{mL}$ each time) to generate a heavy fraction with a $\rho>1.85 \mathrm{~g} \mathrm{~cm}^{-3}$.

\section{Analysis of SOC Content and $\delta^{13} \mathrm{C}$ Values}

All aggregate size classes and fractions obtained by density fractionation, as well as air-dried whole soil samples, were treated with $12 \mathrm{M} \mathrm{HCl}$ for $8 \mathrm{~h} \mathrm{[25],}$ dried at $40^{\circ} \mathrm{C}$, and then weighed to ensure removal of carbonate from the samples before analysis. The treated samples were ground manually and sieved to $<0.15 \mathrm{~mm}$. The $\mathrm{C}$ contents of the bulk soils, aggregate size classes, and isolated density fractions were measured using an elemental analyzer (VARIO EL III, Elementar Co., Ltd; Germany). An isotope ratio

Table 1. Soil properties of soil samples collected from cropland (CL), grassland (GL), and forest (FL).

\begin{tabular}{|c|c|c|c|c|c|}
\hline Horizon $(\mathrm{m})$ & Land use & $\mathrm{pH}$ & $\mathrm{TN}(\mathrm{mg} / \mathrm{kg})$ & $\mathrm{P}(\mathrm{mg} / \mathrm{kg})$ & $\mathrm{K}(\mathrm{mg} / \mathrm{kg})$ \\
\hline \multirow{3}{*}{$0-0.1$} & $\mathrm{CL}$ & 8.44 & 0.50 & 18.1 & 166.0 \\
\cline { 2 - 6 } & GL & 8.49 & 1.55 & 17.3 & 194.8 \\
\cline { 2 - 6 } & FL & 8.28 & 1.20 & 12.6 & 234.0 \\
\hline \multirow{3}{*}{$0.1-0.3$} & CL & 8.51 & 0.52 & 16.7 & 86.1 \\
\cline { 2 - 6 } & GL & 8.48 & 1.05 & 7.6 & 140.2 \\
\cline { 2 - 6 } & FL & 8.55 & 0.57 & 6.2 & 201.9 \\
\hline
\end{tabular}


mass spectrometer (C/N Isotope, Sercon, UK) was used to analyze the natural stable carbon isotope composition of all the samples. The $\mathrm{C}$ isotope ratios were expressed relative to the international $\mathrm{PDB}$ limestone standard as $\delta^{13} \mathrm{C}$.

\section{Analysis of Soil Chemical Properties}

The soil sample was ground and sieved to $<0.15$ $\mathrm{mm}$. Soil $\mathrm{pH}$ was measured using a soil-to-solution (distilled water) ratio of 1:2.5 by a $\mathrm{pH}$ meter (PHS-3C, Shanghai). Total nitrogen (TN), available phosphorus $(\mathrm{P})$, and available potassium $(\mathrm{K})$ were measured according to the methods described by Bao [26].

\section{Statistical Analyses}

All the results were presented as mean \pm standard deviation. Differences in SOC content and the values of $\delta^{13} \mathrm{C}$ in soil samples from different land uses were tested by one-way analysis of variance (ANOVA) using Tukey post hoc test. Data analyses were implemented using SPSS 10.0

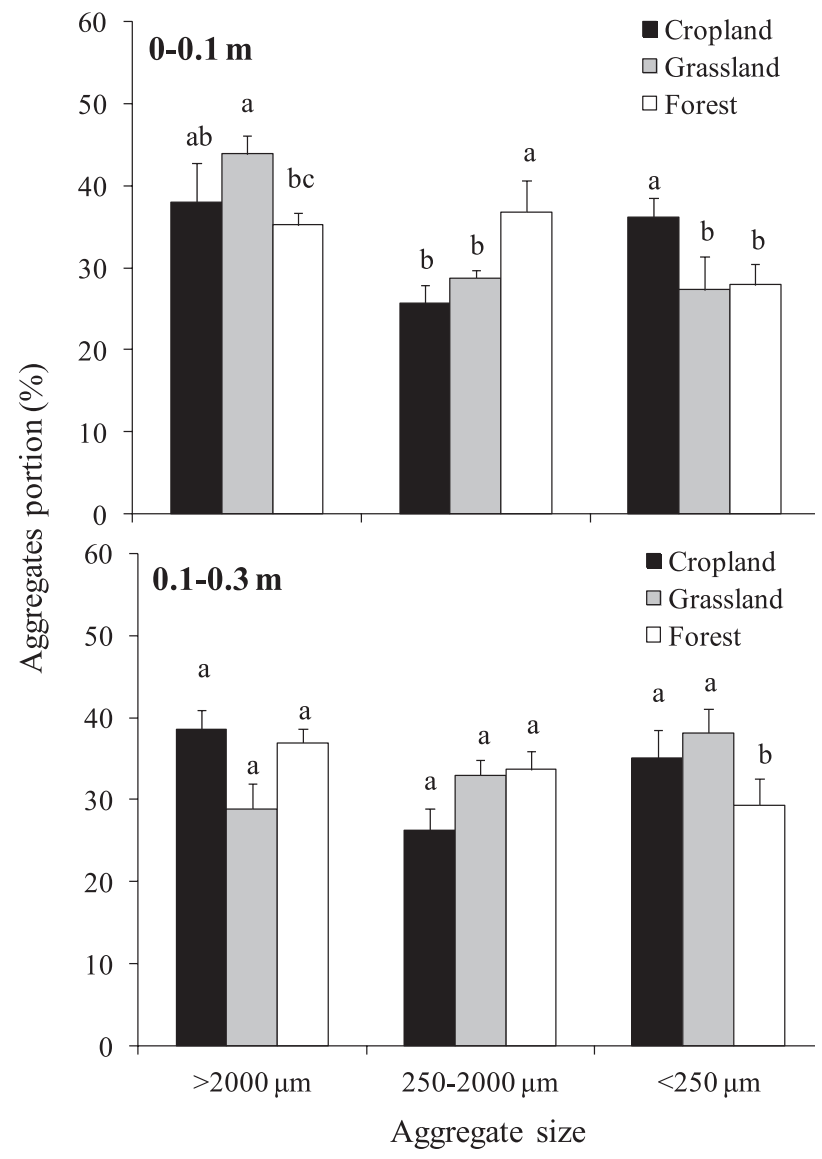

Fig. 2. Aggregate size fraction under different land uses in both topsoil and subsoil; letters at the top indicate significant differences in each aggregate size fraction between land uses $(P<0.05)$

\section{Results and Discussion}

\section{Aggregate Size Fraction}

In the top 0.1-m layer, the proportion of microaggregates in cropland was significantly higher than that in both forest and grassland (Fig. 2). Conversely, the proportion of small macro-aggregates in forest was significantly higher than that in cropland and grassland. Moreover, the proportion of large macro-aggregates in grassland was more than $45 \%$, which was significantly higher than that in forest. At a depth of 0.1-0.3 m, the variation in proportion of aggregate among different land uses was not significant, except that the proportion of micro-aggregates in forest (about $30 \%$ ) was significantly lower than that in cropland and grassland.

Our results showed that soil physical fractions in areas of different land use differed significantly. Similarly, John et al. [27] found that the aggregate fraction of 53-1000 $\mu \mathrm{m}$ was the most abundant size fraction in the arable soils, while the $>1000-\mu \mathrm{m}$ fraction was most abundant in grassland and forest. The mean weighted diameter was greater in the grassland and forest soils than in cultivated soils [28]. Beare et al

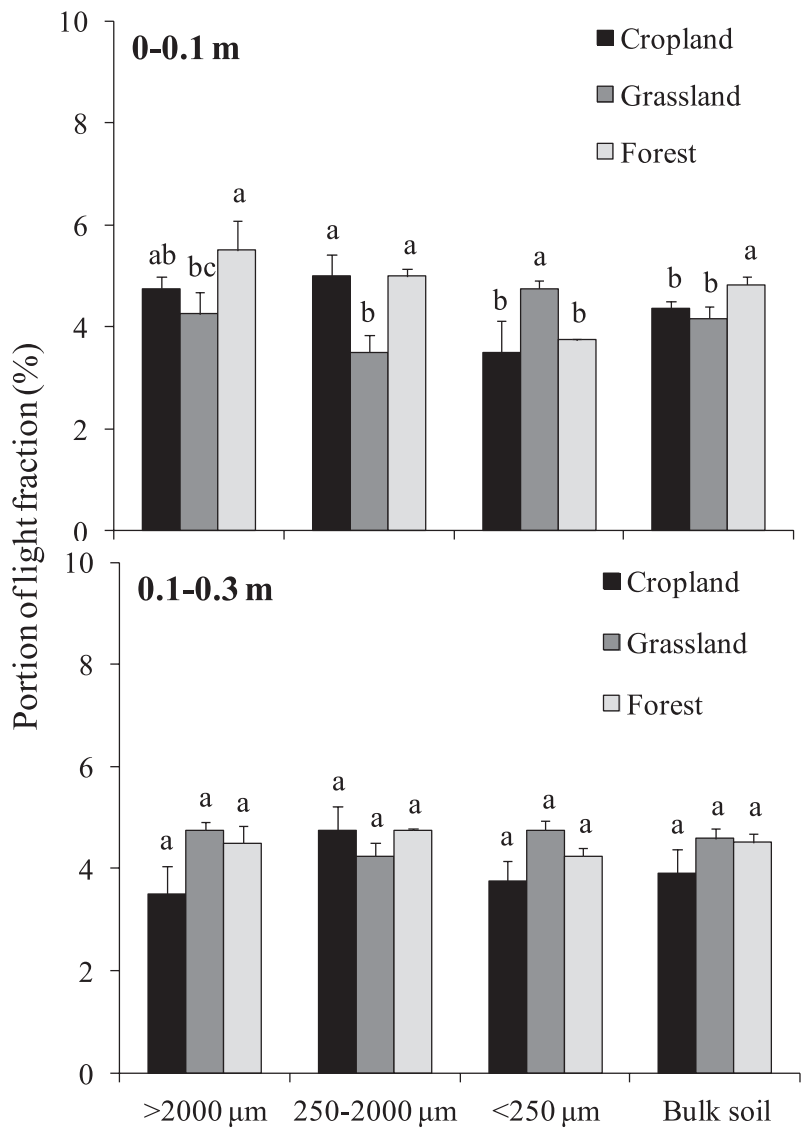

Fig. 3. Proportion of light fraction in varying aggregates under different land uses; letters at the top indicate significant differences in the proportion of light fraction in each aggregate size fraction between land uses $(P<0.05)$. 


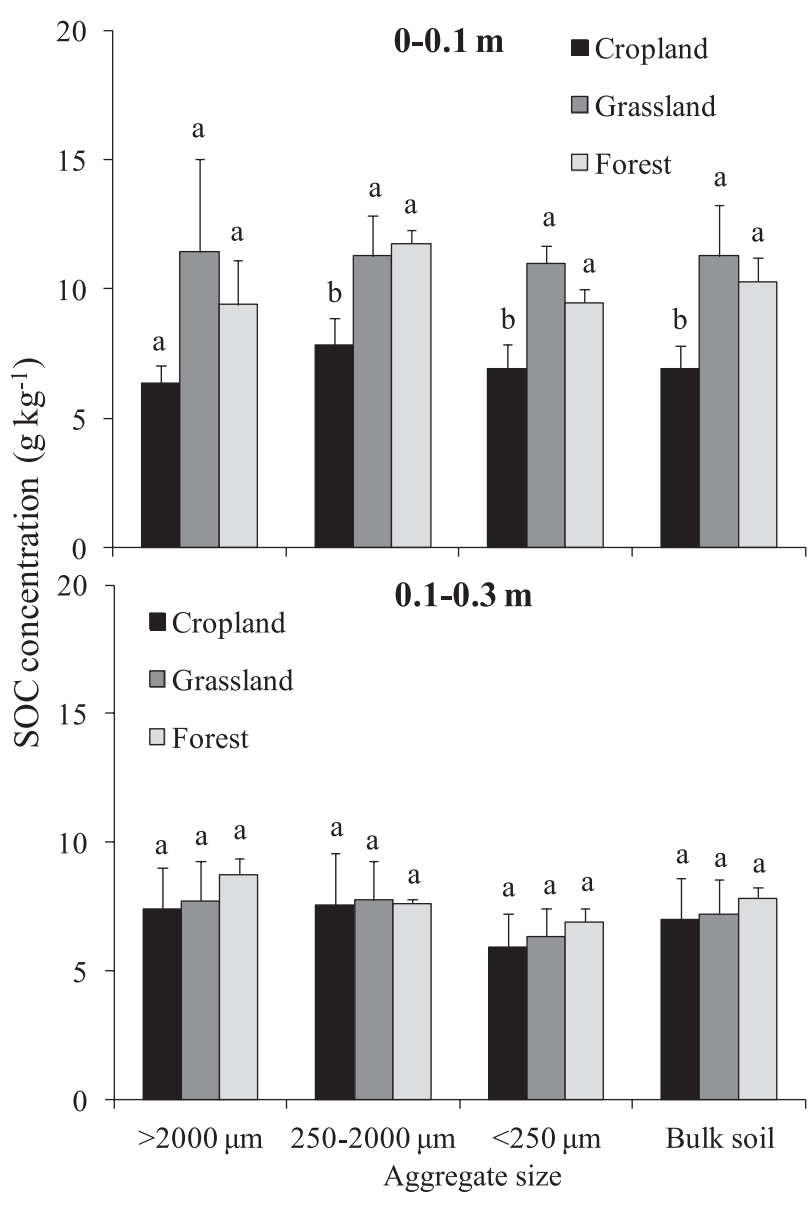

Fig. 4. SOC content in varying aggregates and bulk soil under different land uses; letters at the top indicate significant differences in the SOC content of each aggregate size fraction between land uses $(P<0.05)$.

[29] showed that the proportion of macro-aggregates in conventional tillage was lower than that in no-tillage, indicating that tillage broke up macro-aggregates. Thus, the high proportion of micro-aggregates in cropland may be due to cultivation in cropland because it is an important method of deconstructing macro-aggregates $[3,24]$.

\section{Density Fraction}

The proportion of light fraction in varying aggregates under different land uses is shown in Fig. 3. In the top 0.1-m layer, the proportion of light fraction in the bulk soil in forest was significantly higher than that in cropland and grassland. The proportion of the light fraction in the large macro-aggregate fraction in forest reached $6.0 \%$, which was significantly higher than that in grassland. The proportion of the light fraction in the small macro-aggregate fraction in grassland was significantly lower than that in cropland and forest. However, in the 0.1-0.3 m layer, there was no significant variation in the proportion of light fraction in varying aggregates under different land uses.

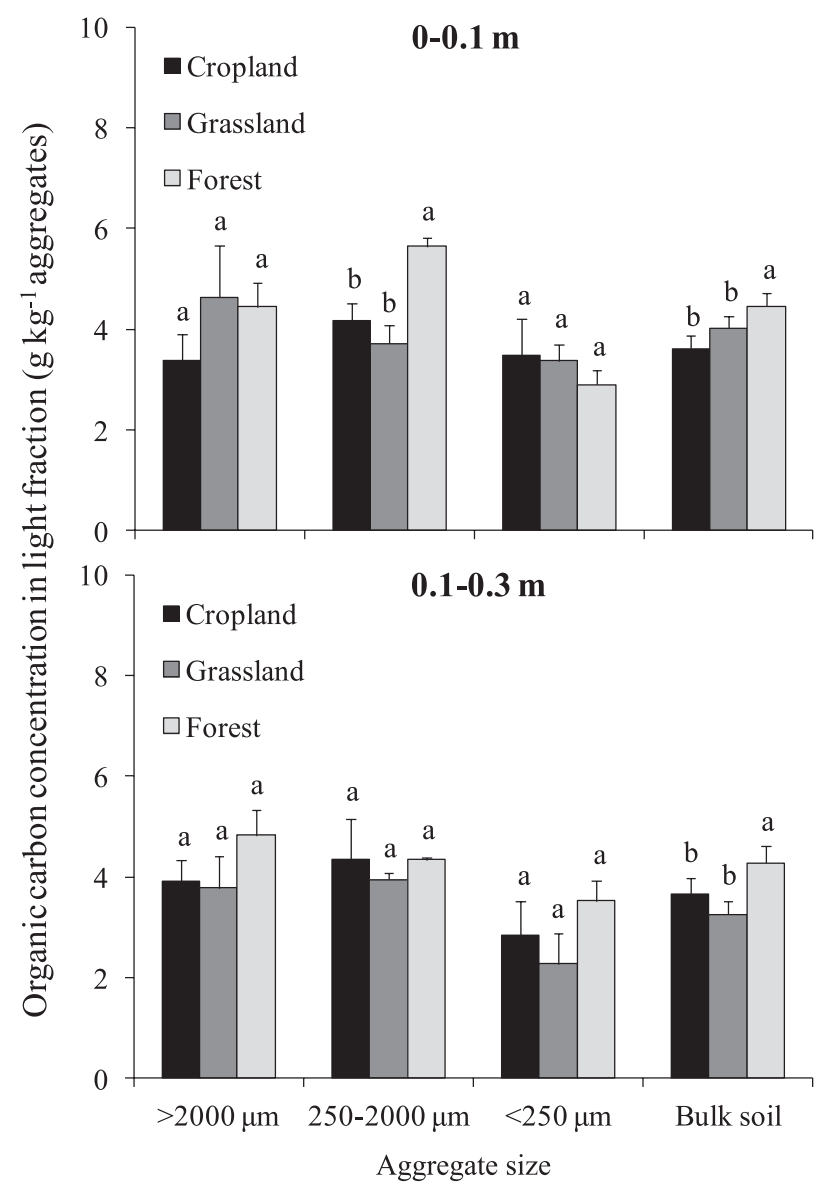

Fig. 5. Organic carbon concentration in light fraction in varying aggregates and bulk soil under different land uses; letters at the top indicate significant differences in the organic carbon concentration in light fraction in each aggregate size fraction between land uses $(P<0.05)$.

\section{Distribution of SOC}

The SOC content in each aggregate and the bulk soil were significantly higher in forest and grassland than in cropland (Fig. 4), except for the value in large macroaggregates. The SOC content in bulk soil in the top $0.1-\mathrm{m}$ layer was $6.9,11.3$, and $10.3 \mathrm{~g} \mathrm{~kg}^{-1}$ in cropland, grassland, and forest, respectively. However, the differences in the SOC contents of aggregates among land uses at the depth of 0.1-0.3 m were not significant. The average value was $7.3 \mathrm{~g} \mathrm{~kg}^{-1}$.

The organic carbon concentration in light fraction in bulk soil in forest was significantly higher than that in cropland in both the top 0.1-m layer and the deeper layer (Fig. 5). The difference in the organic carbon concentration of light fraction in bulk soil between grassland and forest was significant in both the top 0.1-m layer and the deeper layer. The organic carbon content in small macro-aggregate in grassland was significantly higher than that in cropland and grassland in the top 0.1-m layer. Except for this difference, no difference in the organic carbon concentration in light fraction among different aggregates was found. 
Table 2. $\delta^{13} \mathrm{C}$ values of organic matter in light and heavy fractions of aggregates within various size classes for the soils developed under cropland (CL), grassland (GL), and forest (FL)

\begin{tabular}{|c|c|c|c|c|c|}
\hline \multirow{2}{*}{ Horizon (m) } & \multirow{2}{*}{$\begin{array}{c}\text { Land } \\
\text { use }\end{array}$} & \multirow{2}{*}{ Fractions } & \multicolumn{3}{|c|}{ Aggregate size classes $(\mu \mathrm{m})$} \\
\hline & & & $>2000$ & $250-2000$ & $<250$ \\
\hline \multirow{6}{*}{$0-0.1$} & \multirow{2}{*}{$\mathrm{CL}$} & Light fraction & $-20.36 \pm 0.33^{\mathrm{a}}$ & $-20.80 \pm 1.61^{\mathrm{a}}$ & $-22.55 \pm 1.53^{\mathrm{a}}$ \\
\hline & & Heavy fraction & $-15.66 \pm 0.21^{\mathrm{a}}$ & $-18.72 \pm 0.49^{c}$ & $-16.94 \pm 0.38^{b}$ \\
\hline & \multirow{2}{*}{ GL } & Light fraction & $-28.54 \pm 0.34^{b}$ & $-27.82 \pm 0.45^{\mathrm{ab}}$ & $-27.01 \pm 0.68^{\mathrm{a}}$ \\
\hline & & Heavy fraction & $-21.01 \pm 0.16^{\mathrm{a}}$ & $-22.81 \pm 0.10^{c}$ & $-21.92 \pm 0.36^{\mathrm{b}}$ \\
\hline & \multirow{2}{*}{ FL } & Light fraction & $-25.25 \pm 0.06^{\mathrm{a}}$ & $-26.70 \pm 0.46^{\mathrm{b}}$ & $-26.15 \pm 0.27^{b}$ \\
\hline & & Heavy fraction & $-22.29 \pm 0.36^{\mathrm{a}}$ & $-24.19 \pm 0.37^{b}$ & $-21.84 \pm 0.18^{\mathrm{a}}$ \\
\hline \multirow{6}{*}{$0.1-0.3$} & \multirow{2}{*}{ CL } & Light fraction & $-24.35 \pm 0.33^{b}$ & $-24.61 \pm 1.21^{b}$ & $-20.45 \pm 0.90^{\mathrm{a}}$ \\
\hline & & Heavy fraction & $-19.82 \pm 0.61^{b}$ & $-18.66 \pm 0.58^{\mathrm{ab}}$ & $-18.11 \pm 0.65^{a}$ \\
\hline & \multirow{2}{*}{ GL } & Light fraction & $-26.13 \pm 0.45^{\mathrm{ab}}$ & $-26.92 \pm 0.62^{\mathrm{bc}}$ & $-25.58 \pm 0.38^{\mathrm{a}}$ \\
\hline & & Heavy fraction & $-23.03 \pm 0.66^{\mathrm{a}}$ & $-21.81 \pm 0.75^{\mathrm{a}}$ & $-22.14 \pm 0.58^{\mathrm{a}}$ \\
\hline & \multirow{2}{*}{ FL } & Light fraction & $-26.46 \pm 0.65^{\mathrm{a}}$ & $-26.77 \pm 0.46^{\mathrm{a}}$ & $-25.91 \pm 0.27^{\mathrm{a}}$ \\
\hline & & Heavy fraction & $-21.12 \pm 0.50^{\mathrm{b}}$ & $-19.85 \pm 0.49^{\mathrm{a}}$ & $-19.96 \pm 0.45^{\mathrm{a}}$ \\
\hline
\end{tabular}

Lowercase letters indicate significant differences in $\delta^{13} \mathrm{C}$ values between the aggregate size fractions $(\mathrm{P}<0.05)$.

As shown in Fig. 4, the SOC content in the top 0.1-m layer was significantly higher in forest and grassland than in cropland for most aggregate size fractions and the bulk soil. It is well known that SOC content in cropland is very low because of the low carbon input [30, 31]. Celik [28] reported that SOM content in forest and grassland was similar, while Lugo et al. [33] reported that soil in grassland often contained similar or greater amounts of SOC than adjacent mature forest soil. Chen et al. [34] also suggested that land use conversion from cropland to grassland was better for SOC sequestration than tree plantation in the west part of the Loess Plateau. These three studies support the results of the present study, and suggest that the SOC content in grassland is higher than that in forest, or at least similar to that in forest.

However, the differences in SOC contents among land uses were not significant at deeper layers in the current study. Liao et al. [35] also reported similar vertical variations of SOC content in the karst region of Guizhou in southwestern China. Chen et al. [34] suggested that SOC sequestration mainly occurred in the surface soil after land use conversion. In other words, the changes in SOC content in deeper layers were not obvious; thus, the differences in SOC content among land uses were not significant in deeper layers.

\section{Stable Carbon Isotope Composition in Different Fractions}

All values of $\delta^{13} \mathrm{C}$ in the heavy fractions were higher than those in the light fractions (Table 2). The values of $\delta^{13} \mathrm{C}$ in macro-aggregates were significantly $(p<0.05)$ higher than those in micro-aggregates, for most cases at both depths. However, the relationship between large aggregates and macro- (or micro-) aggregates was unclear.

The differences in light and heavy stable carbon isotope composition can reflect the degree of microbial decomposition because isotope fractionation results in ${ }^{13} \mathrm{C}$ enrichment of the residue [36]. In the current study, the difference in $\delta^{13} \mathrm{C}$ between light and heavy fractions in small macro-aggregates was smaller than those in both large macro- and micro-aggregates (Table 2). These results indicated that the degree of microbial decomposition in small macro-aggregates was low. In other words, small macro-aggregates conserve SOC. John et al. [27] also reported that the SOC content in macro-aggregates was much higher than that in micro-aggregates, suggesting that macro-aggregates helped conserve SOC. Tan et al. [23] also suggested that aggregates could protect SOC from disturbance.

Light fraction materials are useful indicators of labile organic matter in soil [37], while the heavy fraction is considered the product of microbial decomposition. The organic carbon concentration in light fraction in bulk soil in forest was significantly higher than that in cropland at both the top 0.1-m layer and the deeper layer, indicating that the new carbon input in forest was much higher than that in cropland. The organic carbon concentration in light fraction in micro-aggregates from grassland was also found to be higher than that in micro-aggregates of forest. This phenomenon suggested that the degradation rate of $\mathrm{OC}$ in micro-aggregates of grassland was higher than that in forest. Similarly, the difference in $\delta^{13} \mathrm{C}$ between the light and heavy fraction in all aggregate size fractions in grassland was much larger than that in forest (Table 2), demonstrating 
Table 3. Relationship among soil chemical properties and organic carbon concentration in bulk soil and light fractions; SOC indicates SOC concentration, LF indicates proportion of light fraction, and OC in LF indicates organic carbon concentration in light fraction.

\begin{tabular}{|c|c|c|c|c|c|c|c|}
\hline & $\mathrm{pH}$ & $\mathrm{TN}$ & $\mathrm{P}$ & $\mathrm{K}$ & $\mathrm{SOC}$ & $\mathrm{LF}$ & OC in LF \\
\hline $\mathrm{pH}$ & 1 & & & & & & \\
\hline $\mathrm{TN}$ & -0.351 & 1 & & & & & \\
\hline $\mathrm{P}$ & -0.178 & 0.059 & 1 & & & & \\
\hline $\mathrm{K}$ & -0.510 & 0.473 & -0.226 & 1 & & & \\
\hline SOC & -0.415 & $0.870 *$ & 0.192 & 0.667 & 1 & & \\
\hline LF & -0.615 & 0.242 & -0.589 & 0.718 & 0.196 & 1 & \\
\hline OC in LF & -0.382 & 0.238 & -0.102 & 0.781 & 0.641 & 0.364 & 1 \\
\hline
\end{tabular}

*Relationship is significant at $\mathrm{P}<0.05$

that microbial decomposition in grassland was high. Liu et al. [38] found that the degradation rate of straw (similar to grass litter) was much higher than that of tree leaves. The heterogeneous distribution of SOC in grassland might also have occurred because the local peak value of SOC stimulated microbial decomposition.

The decrease in SOC in surface soil was considered to be primarily due to the lower supply of organic matter to the soil system. Both grassland and forest had higher carbon input than cropland [31, 32]; however, the SOC content was dependent on both the litter input and microbial decomposition. As stated above, the degree of microbial decomposition was high in grassland but low in forest. Thus, the accumulation of SOC in grassland was derived from the abundant carbon input, but the protection of SOC provided by small macro-aggregates was important for forest soil.

\section{Relationship Among Soil Chemical Properties and SOC}

Table 3 showed the relationship among soil chemical properties and organic carbon concentration in bulk soil and light fractions. The SOC concentration was significantly related to total nitrogen $(\mathrm{TN})$ because $\mathrm{TN}$ was mainly from SOM.

In the current study, dry sieving was used to separate aggregates with minimum disruption. The proportion of small macro-aggregates in forest was significantly higher than that in both grassland and cropland, but the proportion of large macro-aggregates in grassland was highest. The aggregation processes reportedly increased as the SOC content increased [3]; accordingly, the high proportion of small macro-aggregates in forest may be due to the high SOC content (Fig. 4). Different from forest, the high SOC content in grassland resulted in increased amounts of large macro-aggregates, but not small macro-aggregates. Wang et al. [39] revealed that the particle size distribution was more homogeneous in forest than in grassland on the Loess Plateau.

In the current study, stabile and labile carbon was distinguished by density fractions. In future studies, the quantity of content of important biomarkers such as amino acids, lipids, and polysaccharides [40] should be analyzed to provide insight into the dynamics of SOC under various land uses.

\section{Conclusions}

Our results showed that variations in physical fractions and SOC contents occurred in the top 0.1-m layer. Cropland had the highest proportion of microaggregates, whereas forest had the highest proportion of small macro-aggregates. However, grassland always tended to form large macro-aggregates. The difference in $\delta^{13} \mathrm{C}$ between light and heavy fractions in small macro-aggregates was smaller than that in both large macro-aggregates and micro-aggregates. These findings indicated that, when compared with micro- and large macro-aggregates, small macro-aggregates conserve SOC. The difference in $\delta^{13} \mathrm{C}$ between the light and heavy fraction in all aggregate size fractions in grassland was much larger than that in forest, indicating that the degree of microbial decomposition in grassland was high. The physical fractions and stable carbon isotope composition suggested that the accumulation of SOC in grassland was derived from the abundant carbon input, but the protection of SOC from small macro-aggregates was important for forest soil.

\section{Acknowledgements}

This study was sponsored by the National Natural Science Foundation of China (grant No. 41301602) and the Fundamental Research Funds for the Central Universities (Northwest A\&F University, grant Nos. 2452015049, 2452015354, 2452015356, and 41877086). 


\section{References}

1. LAGANIERE J., ANGERS D.A., PARE D. Carbon accumulation in agricultural soils after afforestation: a meta-analysis. Global Change Biol. 16 (1), 439, 2010.

2. BERTHRONG, S.T., PINEIRO G.E.R.V.A.S.I.O., JOBBÁGY E.G., JACKSON R.B. Soil $\mathrm{C}$ and $\mathrm{N}$ changes with afforestation of grasslands across gradients of precipitation and plantation age. Ecological Applications, 22 (1), 76, 2012.

3. YUE C., CIAIS P., LI W. Smaller global and regional carbon emissions from gross land use change when considering sub-grid secondary land cohorts in a global dynamic vegetation model. Biogeosciences Discussions, https://doi.org/10.5194/bg-2017-329, 2017.

4. HOUGHTON R.A., HOUSE J.I., PONGRATZ J. Carbon emissions from land use and land-cover change. Biogeosciences, 9 (12), 5125, 2012.

5. LEITE C.C., COSTA M.H., SOARES-FILHO B.S., HISSA L.D.B.V. Historical land use change and associated carbon emissions in brazil from 1940 to 1995. Global Biogeoch. Cycl., 26 (2), GB2011, 2012.

6. POSPISILOVA L., FORMANEK P., LIPTAJ T., LOSAK T., MARTENSSON A. Land use effects on carbon quality and soil biological properties in Eutric Cambisol. Acta Agriculturae Scandinavica Section B: Soil and Plant Science. 61 (7), 661, 2011.

7. CHANG R., FU B., LIU G., WANG,S., YAO X. The effects of afforestation on soil organic and inorganic carbon: a case study of the Loess Plateau of China. Catena, 95, 145, 2012.

8. LIU S., ZHANG W., WANG K., YIRONG S.U. Evaluation of carbon sequestration after conversion of cropland to forest and grassland projection in karst peak-cluster depression area of northwest Guangxi, China. Acta Ecologica Sinica, 36 (17), 5528, 2016.

9. FANG X., XUE Z., LI B., AN S. Soil organic carbon distribution in relation to land use and its storage in a small watershed of the Loess Plateau, China. Catena, 88 (1), 6, 2012.

10. WANG Y., FU B., LÜ Y., SONG C., LUAN Y. Local-scale spatial variability of soil organic carbon and its stock in the hilly area of the Loess Plateau, China. Quaternary Res. 73 (1), 70, 2010.

11. HAN F., WEI H., ZHENG J., DU F., ZHANG X. Estimating soil organic carbon storage and distribution in a catchment of Loess Plateau, China. Geoderma, 154(3), 261, 2010.

12. PARRAS-ALCÁNTARA L., MARTÍN-CARRILLO M., LOZANO-GARCÍA B. Impacts of land use change in soil carbon and nitrogen in a Mediterranean agricultural area (Southern Spain). Solid Earth, 4 (1), 167, 2013.

13. POEPLAU C., DON A. Sensitivity of soil organic carbon stocks and fractions to different land-use changes across Europe. Geoderma, 192, 189, 2013.

14. FU X., SHAO M., WEI X., HORTON R. Soil organic carbon and total nitrogen as affected by vegetation types in northern loess plateau of china. Geoderma, 155 (1), 31, 2010.

15. CHANG R., FU B., LIU G., LIU S. Soil carbon sequestration potential for "Grain for Green" project in Loess Plateau, China. Environ. Manage. 48 (6), 1158, 2011.

16. FAN T., XU M., SONG S., ZHOU G., DING L. Trends in grain yields and soil organic $\mathrm{C}$ in a long-term fertilization experiment in the China Loess Plateau. J. Plant Nutr. Soil Sci. 171 (3), 448, 2008.

17. ZHANG K., CHENG X., DANG H., YE C., ZHANG Y., ZHANG, Q. Linking litter production, quality and decomposition to vegetation succession following agricultural abandonment. Soil Biol. Bio. 57, 803, 2013.

18. SIX J., PAUSTIAN K., ELLIOTT E. T., COMBRINK C. Soil structure and organic matter I. Distribution of aggregate-size classes and aggregate-associated carbon. Soil Sci. Soc. Am. J. 64 (2), 681, 2000

19. AN S., MENTLER A., MAYER H., BLUM W.E. Soil aggregation, aggregate stability, organic carbon and nitrogen in different soil aggregate fractions under forest and shrub vegetation on the Loess Plateau, China. Catena 81 (3), 226, 2010.

20. GUNINA A., KUZYAKOV Y. Pathways of litter $\mathrm{C}$ by formation of aggregates and SOM density fractions: implications from ${ }^{13} \mathrm{C}$ natural abundance. Soil Biol. Biochem. 71, 95, 2014.

21. DONG X., HAO Q., LI G., LIN Q., ZHAO X. Contrast effect of long-term fertilization on SOC and SIC stocks and distribution in different soil particle-size fractions. J. Soil. Sediment., 17 (4), 1054, 2017.

22. ARAI H., TOKUCHI, N. Soil organic carbon accumulation following afforestation in a Japanese coniferous plantation based on particle-size fractionation and stable isotope analysis. Geoderma, 159 (3-4), 425, 2010.

23. TAN Z., LAL R., OWENS L., IZAURRALDE R.C. Distribution of light and heavy fractions of soil organic carbon as related to land use and tillage practice. Soil Till. Res. 92 (1), 53, 2007.

24. CAMBARDELLA C.A., ELLIOTT E.T. Carbon and nitrogen distribution in aggregates from cultivated and native grassland soils. Soil Sci. Soc. Am. J. 57 (4), 1071, 1993.

25. HARRIS C.M., LOREDANO P., SRO G. pH and kinetic isotope effects in d-amino acid oxidase catalysis. FEBS J. 268 (21), 5504, 2001

26. BAO S. Soil Agrochemical Analysis. China Agriculture Press, Beijing. 2000

27. JOHN B., YAMASHITA T., LUDWIG B., FLESSA $\mathrm{H}$. Storage of organic carbon in aggregate and density fractions of silty soils under different types of land use. Geoderma, 128 (1), 63, 2005.

28. CELIK I. Land-use effects on organic matter and physical properties of soil in a southern Mediterranean highland of Turkey. Soil Till. Res. 83 (2), 270, 2015

29. SINGH M.K., SINGH S., GHOSHAL, N. Impact of land use change on soil aggregate dynamics in the dry tropics. Restor. Ecol., 25 (6), 962, 2017.

30. BEARE M., HENDRIX P.F., COLEMAN D.C. Waterstable aggregates and organic matter fractions in conventional- and no-tillage soils. Soil Sci. Soc. Am. J. 58 (3), 777, 1994.

31. LUO Z., WANG E., BALDOCK J., XING H. Potential soil organic carbon stock and its uncertainty under various cropping systems in Australian cropland. Soil Res., 52(5), 463, 2017.

32. BOLINDERMARTIN A., KÄTTERER T., POEPLAU C., BÖRJESSON G., PARENTLEON E. Net primary productivity and below-ground crop residue inputs for root. Can. J. Soil Sci., 95 (2), $150319043440007,2014$.

33. LUGO A.E., SANCHEZ M.J., BROWN S. Land use and organic carbon content of some subtropical soils. Plant Soil, 96 (2), 185, 1986. 
34. CHEN L., GONG J., FU B., HUANG Z., HUANG Y., GUI L. Effect of land use conversion on soil organic carbon sequestration in the loess hilly area, loess plateau of China. Ecol. Res. 22(4), 641, 2007.

35. LIAO H., LONG J., LI J. Soil organic carbon associated in size-fractions as affected by different land uses in Karst region of Guizhou, Southwest China. Environ. Earth Sci. 74 (9), 6877, 2015.

36. LI Q., WANG H., JIN Z., XIONG W., WU X., ZHANG Y., LIU C. The carbon isotope fractionation in the atmosphere-soil-spring system associated with $\mathrm{CO}_{2}$-fixation bacteria at Yaji Karst experimental site in Guilin, SW China. Environ. Earth Sci., 74 (6), 5393, 2015.

37. WANG X., CAMMERAAT E.L., CERLI C., KALBITZ, K. Soil aggregation and the stabilization of organic carbon as affected by erosion and deposition. Soil Biol. Biochem., 72, 55, 2014.
38. LIU J.X., SUSENBETH A., SÜDEKUM K.H. In vitro gas production measurements to evaluate interactions between untreated and chemically treated rice straws, grass hay, and mulberry leaves. J. Anim. Sci. 80 (2), 517, 2002.

39. WANG D., FU B., ZHAO W., HU H., WANG Y. Multifractal characteristics of soil particle size distribution under different land-use types on the Loess Plateau, China. Catena, 72 (1), 29, 2008.

40. POSPISILOVA L., KOMINKOVA M., ZITKA O., KIZEK R., BARANCIKOVA G., LITAVEC T., LOSAK T., HLUSEK J., MARTENSSON A., LIPTAJ T. Fate of humic acids isolated from natural humic substances. Acta Agriculturae Scandinavica Section B: Soil and Plant Science. 65 (6), 517, 2015. 